\title{
EXISTENCE AND MULTIPLICITY OF SOLUTIONS TO
}

A $p(x)$-LAPLACIAN EQUATION WITH NONLINEAR BOUNDARY CONDITION ON UNBOUNDED DOMAIN

\author{
QIAO LIU AND DUCHAO LIU
}

Abstract. We study the existence and multiplicity of positive solutions for the nonlinear boundary value problems involving the $p(x)$-Laplacian of the form

$$
\begin{cases}-\operatorname{div}\left(a(x)|\nabla u|^{p(x)-2} \nabla u\right)+b(x)|u|^{p(x)-2} u=f(x, u) & \text { in } \Omega \subset \mathbb{R}^{N}, \\ a(x)|\nabla u|^{p(x)-2} \frac{\partial u}{\partial v}=g(x, u) & \text { on } \Gamma=\partial \Omega,\end{cases}
$$

where $\Omega \subset \mathbb{R}^{N}$ is an unbounded domain with non-compact, smooth boundary $\Gamma=\partial \Omega, p \in$ $C^{0,1}(\Omega)$ and $1<p^{-} \leqslant p(x) \leqslant p^{+}<N, a, b$ are suitable weights. By using the variational methods, we prove that there exist multiple solutions provided $f$ and $g$ are given appropriate assumptions.

Mathematics subject classification (2010): 35J35,35J40,35J67,35J70.

Keywords and phrases: $p(x)$-Laplacian equation, nonlinear boundary, weighted variable exponent Lebesgue space, weighted variable exponent Sobolev space, variational method.

\section{REFERENCES}

[1] R.A. Adams And J.F. Fournier, Sobolev space, second edition, Academic Press, (2003).

[2] J. Garcia-Azorero, I. Peral AND I.D. Rossi, A convex-concave problem with a nonlinear bounbary condition, J. Differential Equations, 198 (2004), 91-128.

[3] P. AMSTER, M.C. MARIANI AND O. MENDEZ, Nonlinear boundary conditions for elliptic equations, Electron. J. Differential Equations, 2005 (2005), No. 144, 1-8.

[4] J.F. BOUNDER AND J.D. RossI, Existence results for the p-Laplacian with nonlinear boundary conditions, J. Math. Anal. Appl., 263 (2001), 195-223.

[5] A.C. CAVALHEIRO, Existence of solutions in weighted Sobolev spaces for some degenerate semilinear elliptic equations, Applied Math. Lettles, 17 (2004), 387-391.

[6] F. CîRSTEA, D. MotreAnU AND V. RǍDUlescu, Weak solution of quasilinear problems with nonlinear boundary condition, Nonlinear Anal., 43 (2001), 623-636.

[7] F. CÎRSTEA AND V. RǍDUlescu, Existence and Non-existence Results for a Quasilinear Problem with Nonlinear Boundary Condition, J. Math. Anal. Appl., 244 (2000), 169-183.

[8] X.L. Fan And D. ZhaO, On the Spaces $L^{p(x)}(\Omega)$ and $W^{m, p(x)}(\Omega)$, J. Math. Anal. Appl., 263 (2001), 424-446.

[9] X.L. FAN AND Q.H. ZHANG, Existence of solutions for $p(x)$-Laplacian Dirichlet problem, Nonlinear Anal., 52 (2003), 1843-1852.

[10] X.L. FAn, Solutions for $p(x)$-Laplacian Dirichlet problems with Singular coefficients, J. Math. Anal. Appl., 312 (2005), 464-477.

[11] X.L. Fan And S. G. Deng, Multiplicity of Positive Solutions for a Class of Inhomogeneous Neumann Problems Involving the $p(x)$-Laplacian, Nonlinear differ. equ. appl., 16, 1 (2009), 255-271.

[12] D.A. Kandilakis, A Multiplicity Result For Quasilinear Problems With Convex and Concave Nonlinearities and Nonlinear Boundary Conditions In Unbounded Domains, Electron. J. Differential Equations, 57 (2005), 1-12. 
[13] D.A. KANDilakis AND A.N. Lyderopoulos, Indefinite quasilinear elliptic problems with subcritical and supercritical nonlinearites on unbounded domains, J. Differential Equations, 230 (2006), $337-361$.

[14] O. KovÁČIK And J. RÁKosník, On the Spaces $L^{p(x)}$ and $W^{m, p(x)}$, Czechoslovak Math. J., 41 (1991), 592-618.

[15] Q. Liu, Compact Trace in Weighted Variable Exponent Sobolev Spaces $W^{1, p(x)}\left(\Omega ; v_{0}, v_{1}\right)$, J. Math. Anal. Appl., 348 (2008), 760-774.

[16] W. LiU AND P. ZHAO, Existence of positive solutions for $p(x)$-Laplacian equations in unbounded domains, Nonlinear Anal., 69 (2008), 3358-3371.

[17] C.V. PAO, Nonlinear parabolic and elliptic equations, Plenum Press, New York, London, (1992).

[18] K. PfLÜGER, Semilinear elliptic problems with nonlinear boundary conditions in unbounded domains, Z. Anal. Anwend., 14 (1995), 829-851.

[19] K. PfLÜGER, Nonlinear boundary value problems in Weighted Sobolev spaces, Nonlinear Anal., 30 (1997), 1263-1270.

[20] K. PFLÜGER, Existence and multiplicity of solutions to a p-Laplacian equation with nonlinear boundary condition, Electron. J. Differential Equations, 10 (1998), 1-13.

[21] M. RUU̇ŽIČKA, Electrorheological Fluids Modeling and Mathematical Theory, Springer, (2000).

[22] M. Struwe, Variational Methods, Application to Nonlinear Partial Differential Equations and Hamiltonian Systems, Springer-Verlag Berlin (1990).

[23] M. WILLEM, Minimax Theorems, Birkhäuser, Boston (1996).

[24] J.H. YAO, Solutions for Neumann boundary value problems invoving $p(x)$-Laplace operators, Nonlinear Anal., 68 (2008), 1271-1283.

[25] J.H. ZHAO AND P.H. ZHAO, Infinitely many weak solutions for a $p$-Laplacian equation with nonlinear boundary conditions, Electron. J. Differential Equations, 90 (2007), 1-14.

[26] J.H. ZHAO AND P.H. ZHAO, Existence of infinitely many weak solutions for the p-Laplacian with nonlinear boundary conditions, Nonlinear Anal., 69 (2008), 1343-1355.

[27] Q.H. ZHANG, Existence of radial solution for $p(x)$-Laplacian equation in $R^{N}$, J. Math. Anal. Appl., 315 (2006), 506-516.

[28] V.V. ZhiKov, Averaging of functionals of the calculus of variations and elasticity theory, Math. USSR. Izv., 9 (1987), 33-66. 